\title{
RESEARCH
}

Open Access

\section{NOX1 inhibition attenuates the development of a pro-tumorigenic environment in experimental hepatocellular carcinoma}

Astrid Vandierendonck ${ }^{1 \dagger}$, Helena Degroote ${ }^{1,2^{*}+}$, Bart Vanderborght ${ }^{1,2}$, Xavier Verhelst $^{1}$, Anja Geerts ${ }^{1}$, Lindsey Devisscher ${ }^{2^{*}}$ and Hans Van Vlierberghe ${ }^{1}$

\begin{abstract}
Background: The poor prognosis of advanced HCC and limited efficacy of current systemic treatments emphasize the need for new or combined targeted therapies. The development of HCC is a multistage process in which liver injury appears in a complex microenvironment associated with oxidative stress. NOX enzymes are the main source of ROS during hepatocarcinogenesis and NOX1 in particular has shown correlation with poor prognosis of HCC patients. This study evaluates the effect of pharmacological NOX1 inhibition on the development and progression of HCC and its effect on the tumor microenvironment.

Methods: The in vitro cytotoxic effects of the NOX1 inhibitor GKT771 (Genkyotex) on human Huh7 and Hep3B and murine Hepa1-6 HCC cell lines, the human THP1 monocyte cell line and mouse macrophages were evaluated via MTT, LDH activity and CaspGlo ${ }^{\oplus}$ assays. In order to induce in vivo HCC, male SV129 wild-type mice received weekly IP injections of diethylnitrosamine (DEN) (35 mg/kg) for 20-25 weeks. Mice were treated with vehicle or GKT771 (30 mg/kg) via oral gavage, daily or twice daily, in preventive and therapeutic studies. The liver damage was evaluated for inflammation, angiogenesis, fibrosis and HCC development via histology, RT-qPCR, multiplex analyses and ROS levels.

\footnotetext{
* Correspondence: Helena.degroote@ugent.be; lindsey.devisscher@ugent.be

${ }^{\dagger}$ Astrid Vandierendonck and Helena Degroote contributed equally to this manuscript.

${ }^{1}$ Hepatology Research Unit, Department of Internal Medicine and Pediatrics,

Faculty of Medicine and Health Sciences, Ghent University, Corneel Heymanslaan 10, Blok B, 2nd floor, 9000 Ghent, Belgium

${ }^{2}$ Gut-Liver Immunopharmacology Unit, Department of Basic and Applied Medical Sciences, Faculty of Medicine and Health Sciences, Ghent University, Corneel Heymanslaan 10, Entrance 36 - Floor 3, 9000 Ghent, Belgium
}

(c) The Author(s). 2021 Open Access This article is licensed under a Creative Commons Attribution 4.0 International License, which permits use, sharing, adaptation, distribution and reproduction in any medium or format, as long as you give appropriate credit to the original author(s) and the source, provide a link to the Creative Commons licence, and indicate if changes were made. The images or other third party material in this article are included in the article's Creative Commons licence, unless indicated otherwise in a credit line to the material. If material is not included in the article's Creative Commons licence and your intended use is not permitted by statutory regulation or exceeds the permitted use, you will need to obtain permission directly from the copyright holder. To view a copy of this licence, visit http://creativecommons.org/licenses/by/4.0/. The Creative Commons Public Domain Dedication waiver (http://creativecommons.org/publicdomain/zero/1.0/) applies to the data made available in this article, unless otherwise stated in a credit line to the data. 


\begin{abstract}
(Continued from previous page)
Results: A concentration-dependent reduction in cellular activity of the human HCC cell lines without cytotoxicity was observed. GKT771 treatment reduced LPS-induced pro-inflammatory bone-marrow derived macrophage polarization. DEN injections resulted in $100 \%$ tumor formation and the induction of HCC markers which could be reduced by twice daily dosing of GKT771 at early onset of advanced HCC. DEN-induced HCC resulted in an upregulation of pro-inflammatory, angiogenic and fibrotic markers which was less pronounced in GKT771 treated mice in all treatment regimens. In line, liver fibrosis was induced in HCC mice and this to a lesser extend upon GKT771 treatment.

Conclusions: NOX1 inhibition showed to be safe and well tolerated and was able to attenuate the induction of a pro-inflammatory, angiogenic and pro-fibrotic microenvironment suggesting that this might be a promising adjuvant therapeutic strategy in the treatment of advanced HCC.
\end{abstract}

Keywords: Hepatocellular carcinoma, Oxidative stress, NOX, Tumor microenvironment

\section{Background}

Hepatocellular carcinoma (HCC) is the most common primary liver cancer and represents a major global health problem with increasing incidence and significant cancer-related morbidity and mortality. To date, only a limited number of patients is eligible for curative treatment options, and current therapies for advanced stage HCC have limited efficacy with significant side effects. Consequently, there is an urgent medical need for additional systemic therapeutic options [1].

The development and progression of $\mathrm{HCC}$ is a multistage process in which a chronic insult (e.g. alcohol abuse, viral hepatitis, obesity, cholestatic liver injury) induces liver injury characterized by a micro-environment abundant of various types of cellular stress, including endoplasmic reticulum stress, cellular DNA damage, necrosis of damaged hepatocytes, and oxidative stress with reactive oxygen species (ROS) production. In the liver, ROS are generated in response to a wide variety of endogenous and exogenous stimuli [2-6]. ROS species play multiple biological roles and are therefore involved in a large number of physiological phenomena, such as host defense, but also posttranslational protein processing, cellular signalling, regulation of gene expression, and cellular differentiation [7-9]. Their production is strongly regulated to avoid the harmful effects of a redox imbalance. In a healthy liver, antioxidant systems such as superoxide dismutase and catalase efficiently remove excess of ROS to ensure cellular homeostasis. In contrast, during chronic liver disease, increased ROS production, as well as decreased activity of the antioxidant systems, result in oxidative stress $[10,11]$. Hepatic carcinogenesis is believed to involve ROS-induced DNA damage and/or mitogenic signalling. Liver injurymediated ROS production has been shown to contribute to mutagenesis and genomic instability, resulting in the induction of apoptosis and tissue damage. However, these mutations may also have the potential to activate oncogenes and/or inactivate tumor suppressors, thereby initiating oncogenesis. Thus, chronic liver diseasemediated persistent hepatocyte death establishes a microenvironment that favors survival and proliferation of hepatocytes harboring oncogenic mutations. In addition, when activated, liver resident Kupffer cells (KCs) release an 'oxidative burst' of superoxide and numerous other products with cytotoxic, pro-inflammatory and growth-promoting activity, and attract circulating immune cells to the liver; all contributing to the establishment of a tumor-promoting microenvironment. ROS also contribute to cancer development and progression, by acting as second messengers in disease-driven intracellular signaling pathways controlling cell proliferation, survival, motility and invasiveness, as well as by controlling the reactivity of stromal components that are fundamental for cancer development and dissemination, inflammation, tissue repair, and de novo angiogenesis [11-18].

A number of mechanisms are involved in ROS production. NADPH oxidase (NOX) proteins represent the major non-mitochondrial source of ROS. In addition, there is a growing body of evidence demonstrating that one major effect of inflammation-induced cytokine secretion is the upregulation of ROS-producing NOX isoforms. Seven homologues of the cytochrome subunit of NOX have been described (NOX1-5 and DUOX1-2). NADPH oxidases, with the exception of NOX5, are multimeric complexes, dissociated when inactive, consisting of cytosolic factors (p47phox, NOXO1, p67phox, NOXA1, p40phox, and Rac2) and a redox membrane core. They share the capacity to transport electrons from NADPH to oxygen across the plasma membrane, and to generate superoxide and other downstream ROS. Activation mechanisms, subcellular localization and tissue distribution are highly isoform-dependent $[7,8]$. Various isoforms, such as NOX1, NOX2, and NOX4, are distinctively expressed in specific hepatic cell types, including KCs, hepatic stellate cells (HSCs), endothelial cells, hepatocytes, and infiltrating leukocytes. Genetic and 
pharmacological inhibition of NOX1 has been shown to reduce inflammation and fibrosis in experimental liver disease $[5,6]$. The dual NOX1/4 inhibitor GKT137831 attenuated liver fibrosis, ROS production and the expression of several fibrotic, inflammatory and proliferative genes in different mouse models [19-21]. In a phase I clinical trial, GKT137831 was found to be safe and well tolerated [22]. Non-phagocytic NOX1 is constitutively expressed, although its genetic transcription is upregulated by hypoxia, growth factors, growth-related agonists, inflammatory mediators and pathogen-associated molecular pattern molecules $[8,23]$. Recent research on human HCC samples showed that high NOX1 levels are correlated with a poor prognosis $[24,25]$. The involvement of NOX1 in cell proliferation, tumor growth, cell motility, epithelial-mesenchymal transition (EMT) and matrix metalloproteinase-2 production has been shown in in vitro studies $[13,14]$. NOX1-/- knockout mice and mice with myeloid NOX1 disruption were reported to develop fewer and smaller tumors following diethylnitrosamine (DEN) injection. DEN-injected wild type (WT) mice that received the NOX-1 inhibitor ML171 also developed fewer and smaller hepatic tumor nodules, compared to their vehicle-treated counterparts [26]. This antitumor effect observed in mice treated with a NOX1specific inhibitor may open up new avenues for HCC treatment in humans.

In order to further investigate the role of NOX1 and its potential as a therapeutic target in the treatment of HCC, we studied the effect of the NOX1 inhibitor GKT771 (provided by Genkyotex) in a DEN-induced HCC mouse model, with specific focus on the inflammatory tumor microenvironment (TME).

\section{Materials and Methods}

\section{Nox1 inhibitor - GKT310771}

GKT310771 is a potent, selective and specific NOX1 inhibitor $(\mathrm{Ki}=65 \pm 30 \mathrm{nM})$ with an affinity similar to diphenyliodonium (DPI; $\mathrm{Ki}=70 \pm 5 \mathrm{nM}$ ) that is an irreversible and unspecific flavoprotein inhibitor (Genkyotex, Saint-Julien-en-Genevois, France). GKT310771 is 65 -fold less effective against NOX4 (Ki= $4290 \pm 437 \mathrm{nM})$ and does not inactivate NOX2, NOX3 and NOX5. It is specific for NADPH oxidases over other flavoenzymes and exhibits no ROS scavenging or antioxidant activity according to the absence of affinity for xanthine oxidase and DPPH $(\mathrm{Ki}>100 \mu \mathrm{M})$. An extensive in vitro offtarget pharmacological profiling of GKT310771 against various proteins including ROS-producing and redoxsensitive enzymes, as well as recognized drug targets (GPCRs, kinases, ion channels and others) failed to reveal significant inhibition of any tested candidate when used at $10 \mu \mathrm{M}$, thereby demonstrating high specificity of GKT310771 for NOX enzymes.

\section{HCC cell culture}

The human Hep3B and murine Hepa1-6 cell line were purchased from American Type Culture Collection (ATCC, Molsheim, France). The human Huh-7 cell line was provided by dr. Francesca Fornari [27]. All cell culturing agents and materials were purchased from Life Technologies, Ghent, Belgium; unless stated differently. Cell lines were cultured according to the ATCC guidelines, incubated at $37{ }^{\circ} \mathrm{C}$ under $5 \% \mathrm{CO}_{2}$ and cultured in Dulbecco's Modified Eagle Medium (DMEM; Hep3B and Hepa1-6) or Roswell Park Memorial Institute-1640 (RPMI-1640; Huh-7), supplemented with $10 \%$ Fetal Bovine Serum (FBS) and 1\% Antibiotic Antimycotic Solution (AA; containing 10'000 units penicillin, $10 \mathrm{mg}$ streptomycin and $25 \mu \mathrm{g}$ amphotericin $\mathrm{B}$ per $\mathrm{mL}$ ). For subculturing, cells were dissociated using $0.05 \%$ trypsin, stained with trypan blue, and counted using the LUNA$\mathrm{FL}^{\mathrm{mi}}$ Dual Fluorescence Cell Counter (Logos Biosystems, Annandale, VA, USA).

\section{Cytotoxicity assays}

To determine the concentration-dependent cytotoxicity of the specific NOX1 inhibitor GKT771 (Genkyotex, Saint-Julien-en-Genevois, France), the cells were seeded at a density of $15 \times 10^{3}$ cells per well in 96-well culture plates, and exposed to various GKT771 concentrations $(1.25-100 \mu \mathrm{M}$ in $1 \%$ dimethylsulfoxide (DMSO)enriched culture medium), or equal volumes of solvent, DMSO-free medium or positive controls $(2 \mu \mathrm{M}$ staurosporin for MTT and $2 \%$ Triton-X for LDH) for 24-48 h.

The 3-(4,5-dimethylthiazol-2-yl)-2,5-difenyltetrazolium bromide (MTT) assay (Roche Diagnostics, Anderlecht, Belgium) was used according to the manufacturer's protocol to determine the mitochondrial metabolic activity, a measure for cellular viability. Briefly, cells were incubated with $0.5 \mathrm{mg} / \mathrm{ml}$ MTT for $2 \mathrm{~h}$ at $37{ }^{\circ} \mathrm{C}$. Mitochondrial dehydrogenases degrade MTT into insoluble formazan crystals and the absorbance of these DMSOsolved crystals was measured at $570 \mathrm{~nm}$ against a background control of $630 \mathrm{~nm}$ with a spectrophotometer (Multiskan Ascent). The results are shown as percentages of the solvent-treated control group.

The supernatant of the treated cells was used to measure the lactate dehydrogenase (LDH) activity according to the manufacturer's protocol (Biovision, Milpitas, California, USA). The cytosolic enzyme LDH is released into the culture medium following cytotoxic damagemediated plasma membrane disruption. LDH was quantified via a coupled enzymatic reaction in which LDH catalyses lactate to pyruvate through $\mathrm{NAD}^{+}$reduction. The released NADH is used by diaphorase to reduce a tetrazolium salt into a red formazan product. The absorbance of the latter was measured at $490 \mathrm{~nm}$ against a background control of $630 \mathrm{~nm}$. 
The luminescent CaspGlo ${ }^{\circ}$ 3/7 (Promega, Leiden, The Netherlands) was used to measure caspase- 3 and -7 activities of the different adherent cell cultures. Upon cell lysis, the proluminescent caspase-3/7 substrate, which contains the tetrapeptide sequence DEVD, is cleaved by caspase-3/7. This releases aminoluciferin, which in turn is used by luciferase for the production of light, allowing quantification of the apoptotic state of the cell cultures. All cells were incubated in the dark for $2 \mathrm{~h}$ with the CaspGlo $^{\circ}$ 3/7 reagent prior to detection with a luminometer (Fluostar, BMG Labtech, De Meern, The Netherlands).

\section{Mouse BMDM and human monocyte cell line THP1}

Murine bone marrow-derived macrophage single cell isolates were obtained from mice by flushing the femurs and tibiae with ice-cold phosphate-buffered saline (PBS). After centrifugation ( $7 \mathrm{~min} ; 1200 \mathrm{rpm} ; 4^{\circ} \mathrm{C}$ ), the pellet was resuspended in pre-heated $\left(37^{\circ} \mathrm{C}\right)$ DMEM supplemented with $20 \mathrm{ng} / \mathrm{ml}$ murine macrophage colonystimulating factor (M-CSF, PeproTech, London, UK), $50 \mu \mathrm{g} / \mathrm{ml} \mathrm{Gentamycin} \mathrm{(from} 3 \mathrm{mg} / \mathrm{ml}$ stock), $10 \%$ FBS and $1 \% \mathrm{AA}$. Cells were seeded in two $10 \mathrm{~cm}$ petri dishes per mouse, with each containing approximately $20 \times 10^{6}$ primary bone marrow-derived macrophages (BMDMs) after 7 days of culturing. Medium was refreshed every other day and cells were collected using enzyme-free dissociation buffer. For the human THP1 monocyte cell line, cells were cultured in suspension in RPMI-1640 supplemented with $10 \%$ FBS. Prior to treatment with GKT771, cells were seeded into well-plates and stimulated with 12-O-tetradecanoylphorbol-13-acetate (PMA, $10 \mathrm{ng} / \mathrm{ml}$ ) to allow differentiation into macrophages. Concentration-dependent cytotoxicity of GKT771 with and without lipopolysaccharide (LPS)-stimulation $(1 \mu \mathrm{g} /$ $\mathrm{ml}$; Sigma-Aldrich) on mouse and human macrophages was determined via the MTT and LDH assay, as described above.

\section{Mice}

All animal experiments were reviewed and approved by the Animal Ethics Committee of the Faculty for Medicine and Health Sciences, University Ghent (ECD18/50). Five-week-old male SV129 wild-type mice, purchased from Janvier Labs (Le Genest-Saint-Isle, France), were housed at room temperature and constant humidity in a 12-hour controlled dark/light cycle at the animal facility of the Faculty of Medicine and Health Sciences, Ghent University, Belgium. Mice received standard chow (Pavan Service-Carfil, Oud-Turnhout, Belgium) and water ad libitum before and during the experiment. The welfare of all animals was evaluated daily and the mice were weighted weekly, during the entire duration of the experiment.

\section{Preparation of vehicle and dose formulation}

Vehicle consisted of deionized water containing $1.2 \mathrm{w} \%$ methylcellulose and $0.1 \mathrm{w} \%$ Polysorbate 80 (Tween 80), which was stirred overnight at $4{ }^{\circ} \mathrm{C}$ to allow complete solubilisation. GKT771 was dissolved in vehicle solution. Both solutions were stored at $4{ }^{\circ} \mathrm{C}$, protected from light and stirred for at least 10-15 minutes before oral administration (dosage of $30 \mathrm{mg} / \mathrm{kg}$ ).

\section{Preventive study}

In order to induce HCC, mice received weekly intraperitoneal (IP) injections of saline or diethylnitrosamine (DEN; $35 \mathrm{mg} / \mathrm{kg}$, Sigma-Aldrich, Diegem, Belgium) for 25 weeks. At week 15, mice were randomised into 4 treatment groups and treated for 15 weeks: vehicletreated healthy saline controls $(n=6)$, GKT771-treated healthy saline controls $(n=4)$, vehicle-treated DENinduced HCC mice $(n=7)$ and GKT771-treated DENinduced HCC mice $(n=10)$. Mice were treated daily via oral gavage. At week 30 of the experiment, mice were sacrificed (Fig. 1a).

\section{Therapeutic study}

Two different treatment regimens were applied in the therapeutic setting of the experimental set-up. As in the preventive setting, mice received weekly IP injections of saline or DEN. This was maintained for 25 weeks in the early treatment regimen and 20 weeks in the delayed treatment regimen. Since HCC nodules are macroscopically visible as soon as 20 weeks of DEN [28], an early treatment regimen was started in which mice were planned to be treated with vehicle $(n=11)$ or GKT771 $(n=9)$ twice daily via oral gavage for a total of 10 weeks. However, due to ethical reasons, early euthanasia was performed after 9 weeks. A second treatment regimen was set up in which mice were kept in a resting period of 2 weeks after the final DEN injection at week 20. During this delayed treatment regimen, mice were treated daily with vehicle $(n=5)$ or GKT771 $(n=6)$ for 5 weeks via oral gavage (Fig. 1b).

\section{Sample collection}

At the day of sacrifice, mice were weighted, and anesthetized by intraperitoneally injecting a ketamine $(100 \mathrm{mg} /$ $\mathrm{kg})$ - xylazine $(10 \mathrm{mg} / \mathrm{kg})$ solution for blood sampling. The mice were euthanized via cervical dislocation prior to dissection. Both spleen and liver were isolated and weighed, after which the number of nodules was macroscopically evaluated. The lesions of the mice from the preventive study and of the treatment regimen 2 of the therapeutic study were manually separated from the non-tumorous liver tissue. Liver tissue without tumors, the tumors and the total livers were divided into different sections for further analyses. Sections for RNA 


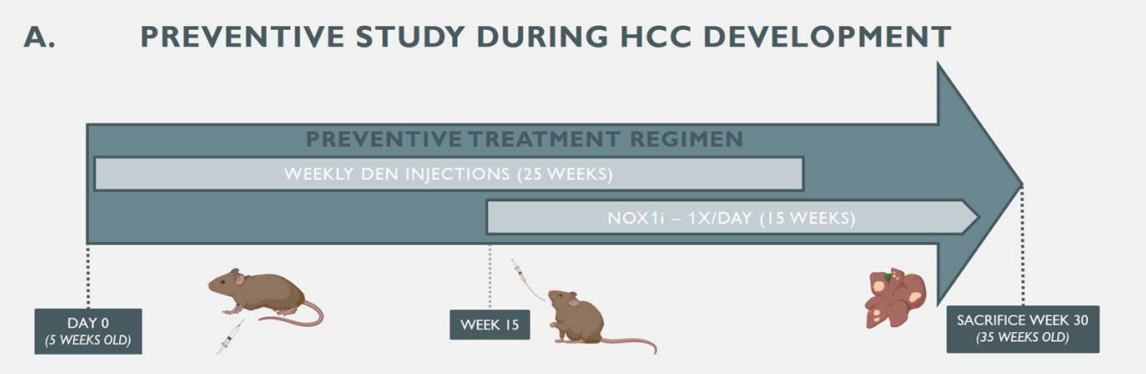

B. THERAPEUTIC STUDY IN ESTABLISHED ADVANCED HCC

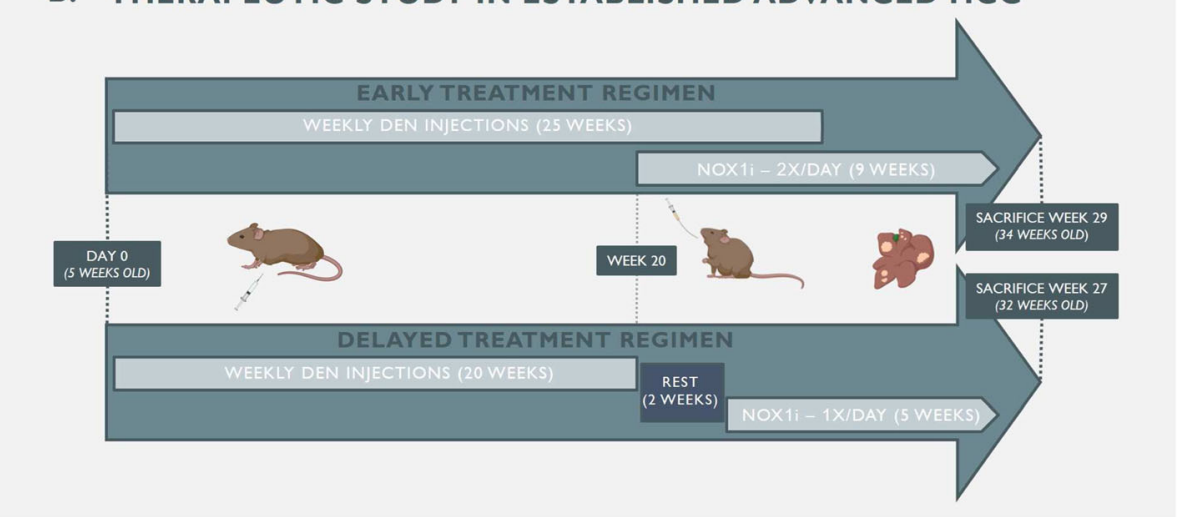

Fig. 1 Timeline of in vivo GKT771 studies in DEN-induced HCC. a In the preventive study, five-week-old male SV129 wild-type received intraperitoneal injections of saline or $35 \mathrm{mg} / \mathrm{kg}$ DEN for 25 weeks to induce HCC. During HCC development (week 15 of DEN), mice were treated daily with vehicle or GKT771 (30 mg/kg) via oral gavage for 15 weeks. $\mathbf{b}$ In the therapeutic studies, mice received weekly DEN injections for 25 weeks or 20 week in the early and delayed treatment regimen, respectively. In the early treatment regimen, mice were treated with GKT771 twice daily after 20 weeks of DEN for a total of 9 weeks (early euthanasia). Mice in the delayed treatment regimen were kept in a resting period of 2 weeks after the final DEN injection prior to daily GKT771 treatment for 5 weeks

analysis were collected in RNA-later, snap-frozen using liquid nitrogen and stored at $-80{ }^{\circ} \mathrm{C}$ until further analysis. Tissue sections for histological examination were collected in cassettes and fixed in a $4 \%$ phosphate-buffered formaldehyde solution, and embedded in paraffin.

\section{Total RNA extraction}

For the quantification of specific gene transcript levels, needle homogenisation was performed on all tissue samples prior to lysis with RLT lysis buffer supplemented with $\beta$ mercaptoethanol (Biorad, Temse, Belgium). Total RNA was extracted from all samples using the Aurum ${ }^{\text {max }}$ Total RNA Mini Kit according to the manufacturer's Spin Format Guidelines (Biorad, Temse, Belgium). The purity and quantity of total RNA was assessed using spectrophotometry (Nanodrop, Thermo Scientific, Wilmington, USA). Purity was determined using the ratio of absorbance at 260 and $280 \mathrm{~nm}$ (only ratios between 1.8 and 2.0 were accepted).

\section{Quantitative real-time polymerase chain reaction}

One microgram of total RNA was converted to single strand cDNA by reverse transcription (Sensifast cDNA synthesis kit, Bioline Reagents Ltd, Kampenhout,
Belgium), following the cDNA Bio thermocycler program $\left(10^{\prime} 25^{\circ} \mathrm{C}, 15^{\prime} 42^{\circ} \mathrm{C}, 5^{\prime} 85^{\circ} \mathrm{C}\right)$. The cDNA was diluted $1 / 10$ prior to real-time quantification via reverse transcriptase quantitative real-time polymerase chain reaction (RT-qPCR) using SYBR Green (NO-ROX, Sensimix, Bioline Reagents Ltd., Waddinxveen, The Netherlands) according to the manufacturer's guidelines. All reactions were performed in duplicate. All used primer sequences (Biolegio, Nijmegen, The Nederlands) are listed in Table 1. A real-time cycling program (initial denaturation: $10^{\prime} 95^{\circ} \mathrm{C}$; 40 PCR cycles: denaturation 10 " $95{ }^{\circ} \mathrm{C}$ and annealing/extension/fluorescence reading $60^{\prime \prime}$ $60{ }^{\circ} \mathrm{C}$ ) was run on a Lightcycler 480 II (Roche, Machelen, Belgium) and melting curve analysis was performed to assess primer specificity. The threshold cycle $(\mathrm{Ct})$ values were further analysed using the $2^{-\Delta \Delta C T}$ method. In short, the average of the in duplo $\mathrm{Ct}$ values of the household and target genes were calculated. The geometric mean of these values of the stable household genes (determined via GeNorm) were calculated and subtracted from the in duplo averages of the target genes $(=\Delta \mathrm{Cp})$. Next, the mean of the $\Delta \mathrm{Cp}$ of the control samples was subtracted from the $\Delta \mathrm{Cp}$ of each individual 
Table 1 Primers used for the mRNA expression analyses conducted on the murine BMDM and liver tissue samples

\begin{tabular}{|c|c|c|c|c|}
\hline Marker & Gene ID & Gene name & Forward primer & Reverse primer \\
\hline \multirow[t]{5}{*}{ Inflammation } & CCR2 & C-C Motif Chemokine Receptor 2 & ATCCACGGCATACTATCAACATC & CAAGGCTCACCATCATCGTAG \\
\hline & CCL2 & C-C Motif Chemokine Ligand 2 & TTAAAAACCTGGATCGGAACCAA & GCATTAGCTTCAGATTTACGGGT \\
\hline & IL6 & Interleukin 6 & TAGTCCTTCCTACCCCAATTTCC & TTGGTCCTTAGCCACTCCTTC \\
\hline & $\operatorname{IL} 1 \beta$ & Interleukin 1 beta & $\begin{array}{l}\text { CAACCAACAAGTGATATATTCTCC } \\
\text { ATG }\end{array}$ & GATCCACACTCTCCAGCTGCA \\
\hline & TNFa & Tumor Necrosis Factor alpha & CATCTTCTAAAATTCGAGTGACAA & $\begin{array}{l}\text { TGGGAGTAGACAAGGTAC } \\
\text { AACCC }\end{array}$ \\
\hline \multirow[t]{3}{*}{ Inflammasome } & iNOS & Inducible Nitric Oxide Synthase & GGCAGCCTGTGAGACCTTTG & GCATTGGAAGTGAAGCGTTC \\
\hline & NLRP3 & $\begin{array}{l}\text { Nod-, LRR- and Pyrin domain-containing Pro- } \\
\text { tein } 3\end{array}$ & ATCAACAGGCGAGACCTCTG & GTCCTCCTGGCATACCATAGA \\
\hline & $\begin{array}{l}\text { Caspase } \\
1\end{array}$ & Caspase 1 & AATACAACCACTCGTACACGTC & AGCTCCAACCCTCGGAGAAA \\
\hline $\begin{array}{l}\text { Immune } \\
\text { suppression }\end{array}$ & PDL1 & Programmed death-ligand 1 & GACGCAGGCGTTACTGCT & GCGGTATGGGGCATTGACTIT \\
\hline \multirow[t]{2}{*}{$\mathrm{HCC}$} & AFP & Alphafetoprotein & AGCTTCCACGTTAGATTCCTCC & ACAAACTGGGTAAAGGTGATGG \\
\hline & GP3 & Glypican 3 & TCGACAGCCTCTTTCCCAGTCA & GGTCACGTCTTGCTCCTCG \\
\hline \multirow[t]{4}{*}{ Stemness } & MDR1 & Multidrug Resistance 1 & AGCCGTAAGAGGCTGAGGCCG & TCACGTGCCACCTCCGGGTT \\
\hline & EPCAM & Epithelial Cell Adhesion Molecule & GCGGCTCAGAGAGACTGTG & CCAAGCATTTAGACGCCAGTTT \\
\hline & CD44 & Cluster of Differentiation 44 & TCGATTTGAATGTAACCTGCCG & CAGTCCGGGAGATACTGTAGC \\
\hline & CD133 & Cluster of Differentiation 133 & CTCCCATCAGTGGATAGAGAACT & ATACCCCCTITGACGAGGCT \\
\hline \multirow[t]{4}{*}{ Angiogenesis } & CD31 & Cluster of Differentiation 31 & TGCCTTGTTCATGTTGGGTA & CCTCAGAATATTCCAGGGCA \\
\hline & END & Endoglin & CCACCGGCCATGAACTTGTCCC & $\begin{array}{l}\text { AGTGGGGTGAGGAGATCC } \\
\text { CAAGG }\end{array}$ \\
\hline & iCAM & Intercellular Adhesion Molecule 1 & GCCTTGGTAGAGGTGACTGAG & GACCGGAGCTGAAAAGTTGTA \\
\hline & VCAM & Vascular Cell Adhesion Protein 1 & TGCCGAGCTAAATTACATATTG & CCTTGTGGAGGGATGTACAGA \\
\hline \multirow[t]{3}{*}{ Fibrosis } & aSMA & Alpha-Smooth Muscle Actin & CCAGCACCATGAAGATCAAG & TGGAAGGTAGACAGCGAAGC \\
\hline & COL1A1 & Collagen type 1 alpha & GCTCCTCTTAGGGGCCACT & CCACGTCTCACCATTGGGG \\
\hline & TGF $\beta$ & Transforming Growth Factor beta & TGAGCGTCACTGGAGTTGTACGG & GGTTCATGTCATGGATGGTGC \\
\hline
\end{tabular}

sample $(=\Delta \Delta \mathrm{Cp})$ and the power was calculated (= $\left.2^{-\Delta \Delta C T}\right)$. All expression analysis graphs display these powers, and statistical analysis was performed on the normalized $\log _{10}$ transformed data of these powers. Statistical analyses were performed as described below.

\section{Luminex}

Snap-frozen liver tissue was defrosted in $1 \mathrm{mg} / \mathrm{mL}$ protease inhibitor cocktail (cOmplete ${ }^{\mathrm{rm}}$, Mini, EDTA-free Protease Inhibitor Cocktail, 04693159 001, Roche, Sigma-Aldrich, Overijse, Belgium), 1 v\% phosphatase inhibitor cocktail 2 (P5726, Sigma-Aldrich, Overijse, Belgium) and $1 \mathrm{v} \%$ phosphatase inhibitor cocktail 3 (P0044, Sigma-Aldrich, Overijse, Belgium) in PBS, lysed by sonication and centrifuged for $15 \mathrm{~min}$ by $15,000 \mathrm{rpm}$ at $4{ }^{\circ} \mathrm{C}$. Supernatant was stored at $-80{ }^{\circ} \mathrm{C}$ until further analysis. Total protein concentrations were measured by BCA protein assay following manufacturer's guidelines (DC protein assay, 500-0116, Bio-Rad, Temse,
Belgium). Protein levels of TNF- $\alpha$, MCP-1/CCL2 and IL6 were determined by using Bio-plex Pro Reagent Kit and Luminex microbeads (Biorad, Temse, Belgium) according to the manufacturer's guidelines.

\section{ROS assay}

Hepatic tissue lysates were prepared by defrosting snapfrozen liver tissue in PBS prior to sonication on ice. The lysates were centrifuged for $5 \mathrm{~min}$ by $10,000 \mathrm{~g}$ at $4{ }^{\circ} \mathrm{C}$. The supernatant was used for the quantification of ROS levels, which was performed using a commercial DCF ROS/RNS Assay Kit (Ab238535, Abcam, Cambridge, United Kingdom,) according to the manufacturer's instructions.

\section{Histological analysis}

After deparaffinization and rehydration of the tissue samples, sections of $5 \mu \mathrm{m}$ of paraffin-embedded liver tissue were stained with Sirius Red (Sigma-Aldrich) for histopathological examination according to the Metavir 
scoring system. This system allows to assess the extent of fibrosis in our liver samples, which was visualised using the $\mathrm{Cell}^{\wedge} \mathrm{D}$ software (Olympus).

\section{Statistical analysis}

Statistical analyses were performed using GraphPad Prism 8 (GraphPad Software, California, USA). Normality was tested using the D'Agostino \& Pearson omnibus test. Outliers were identified with the ROUT method and were removed for further analysis. The maximum desired false discovery rate was set to $1 \%$. Gaussian distributed data of two groups were compared via t-tests and multiple groups were compared by one-way analysis of variance (ANOVA) test and corrected with the HolmSidak test. Non-normally distributed data were either transformed to Gaussian distribution via LOG $_{10}$-transformations or analysed via Kruskal Wallis tests for multiple comparison. Data are presented as the fold change relative to expression in controls as mean $\pm \mathrm{SD}$, unless stated differently in the figure legends. P-values are reported two-sided and considered significant when less than $0.05\left(* p<0.05,{ }^{* * *} p<0.01,{ }^{* * * * *} p<0.001,{ }^{* * * * * * *} p<\right.$ 0.0001).

\section{Results}

Moderate doses of GKT771 treatment do not induce HCC cell cytotoxicity in vitro

To assess the potential cytotoxic effects of NOX1 inhibition in vitro, two human HCC cell lines (Huh7 and Hep3B) were treated for 24 hours with various concentrations of GKT771, ranging from 0 to $100 \mu \mathrm{M}$. Mitochondrial metabolism was examined as an indicator of cell viability using the MTT assay, and was found to be significantly reduced in a concentration dependent manner in both cell lines (Fig. 2a \& d). No loss of membrane integrity or increase in caspase $3 / 7$ activity could be detected using an $\mathrm{LDH}$ and $\mathrm{CaspGlo}$ assay respectively, which indicates the absence of cell lysis or apoptotic cell death of human HCC cells upon treatment with GKT771 at concentrations up to $100 \mu \mathrm{M}$ (Fig. 2b-c \& e-f).

Identical analyses following a similar GKT771 treatment regimen in the murine Hepa1-6 HCC cell line

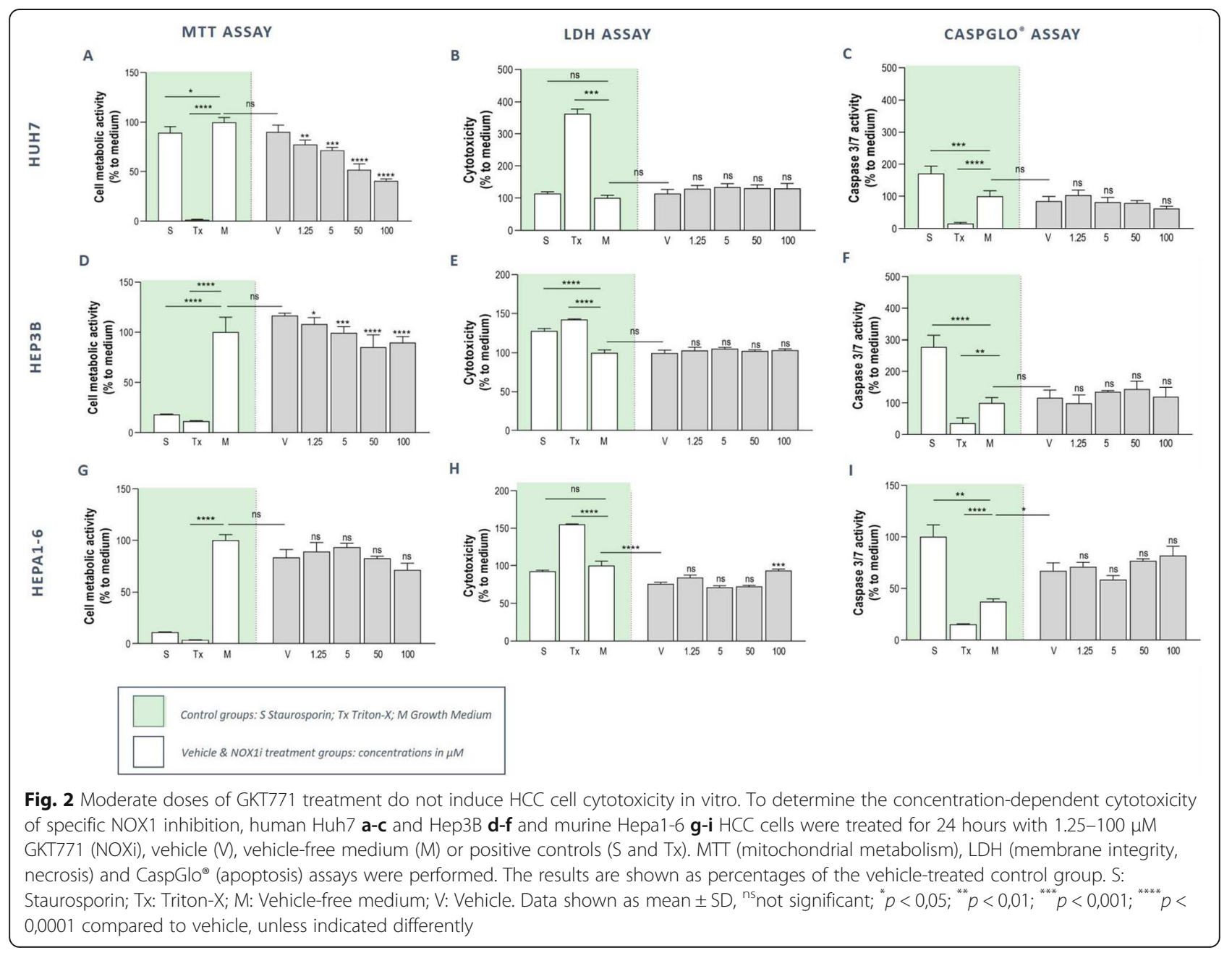


revealed no significant alterations in mitochondrial metabolism and caspase 3/7 activity (Fig. $2 \mathrm{~g} \& \mathrm{i}$ ). However, an impaired cellular membrane integrity could be observed at $100 \mu \mathrm{M}$, indicating the presence of a moderate toxic effect at the highest concentration (Fig. 2h).

\section{NOX1 inhibition attenuates LPS-induced macrophage polarization}

Murine bone marrow-derived single cell isolates and THP1 cells were seeded in medium containing M-CSF or PMA respectively, to induce proliferation and differentiation into macrophages. The resulting primary BMDMs and THP1 macrophages were treated with $100 \mu \mathrm{M}$ of GKT771 with and without LPS-stimulation. MTT and LDH analyses showed a significant enhancement of the mitochondrial metabolic state associated with a disruption of cellular membrane integrity of GKT771-treated BMDMs in both the presence and absence of LPS (Fig. 3a). In the human monocyte cell line THP1, GKT771 induced a decrease in cell metabolic activity and increased cytotoxicity, in both the presence and absence of LPS (Fig. 3b).

To assess the effect of NOX1 inhibition on the polarization of BMDMs in vitro, the mRNA expression of inflammatory markers (CCL2, IL6, IL1 $\beta$, TNF $\alpha$, iNOS, NLRP3 and Caspase 1) and of the immune suppressive marker PDL1 was examined via RT-qPCR upon treatment of these cells with $100 \mu \mathrm{M}$ of GKT771, with and without LPS. LPS activation of the murine BMDMs resulted in a significant increased expression of the analysed markers which was significantly less pronounced in combination with NOX1 inhibition for CCL2, IL6, IL1 $\beta$, iNOS, NLRP3 and Caspase 1 (Fig. 3c). Our results were confirmed in the human monocyte cell line THP1 for the inflammatory markers CCL2, IL6, IL1 $\beta$ and TNFa (Fig. 3d). This shows that NOX1 inhibition is able

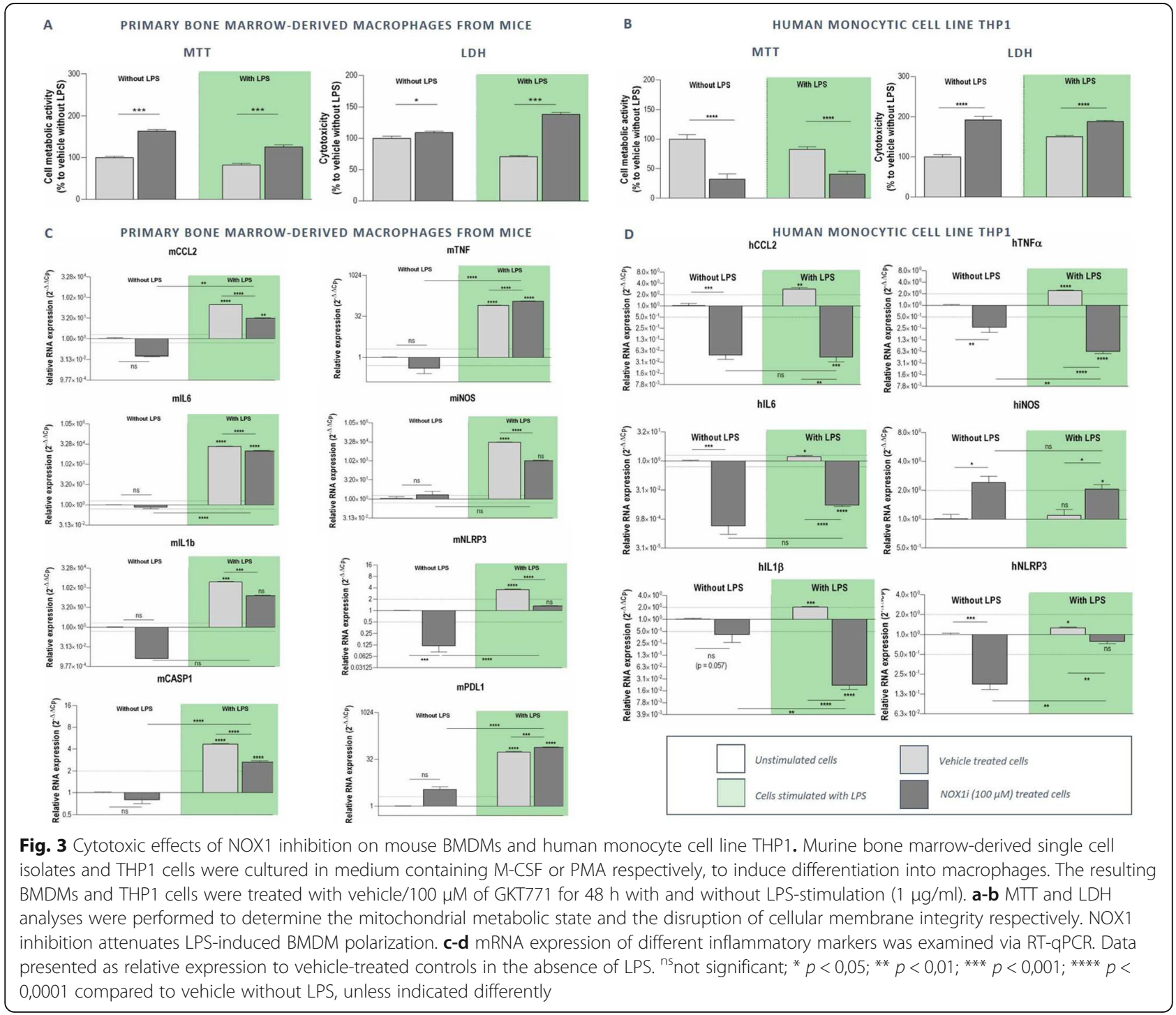


to attenuate LPS-induced polarization in both murine BMDM and the human monocyte cell line THP1.

NOX1 inhibition attenuates the development of a protumorigenic microenvironment during HCC development Mice received weekly IP injections of DEN for 25 weeks. At week 15, daily treatment with GKT771 was initiated to evaluate the effect of NOX1 inhibition on tumor development. DEN administration resulted in a mild decrease in body weight and a moderately elevated spleen weight (not significant). As expected, DEN administration induced macroscopically visible tumoral lesions in the liver of both vehicle and GKT771 treated mice, while in the healthy control groups (saline) no lesions were detected. Preventive GKT771 treatment did not significantly alter the total number of tumor lesions in the liver (Fig. 4a-b). In line, the expression of two HCC markers, AFP and GP3, was induced in tumor and surrounding liver tissue of both vehicle and GKT771 treated HCC mice (Fig. 4c). However, significant induction of hepatic cancer stem cell markers (MDR1, EPCA M, CD44 and CD133) in the tumors and surrounding liver tissue was attenuated upon GKT771 treatment (Fig. 4c).

DEN-induced HCC resulted in an induced expression of inflammatory markers IL6, TNF $\alpha$, IL1 $\beta$, CCR2, CCL2, Caspase 1 and NLRP3, and of the immune suppressive marker PDL1, compared to healthy control liver tissue (Fig. 5). This induction was most explicit and significant in the tumor lesions, but also present in surrounding liver tissue. Preventive administration of GKT771 resulted in a less pronounced induction of these markers, both in tumor lesions and surrounding tissue (Fig. 5).

To further evaluate the effect of GKT771 on the progressing tumoral microenvironment, mRNA expression analysis of angiogenic and fibrotic markers was

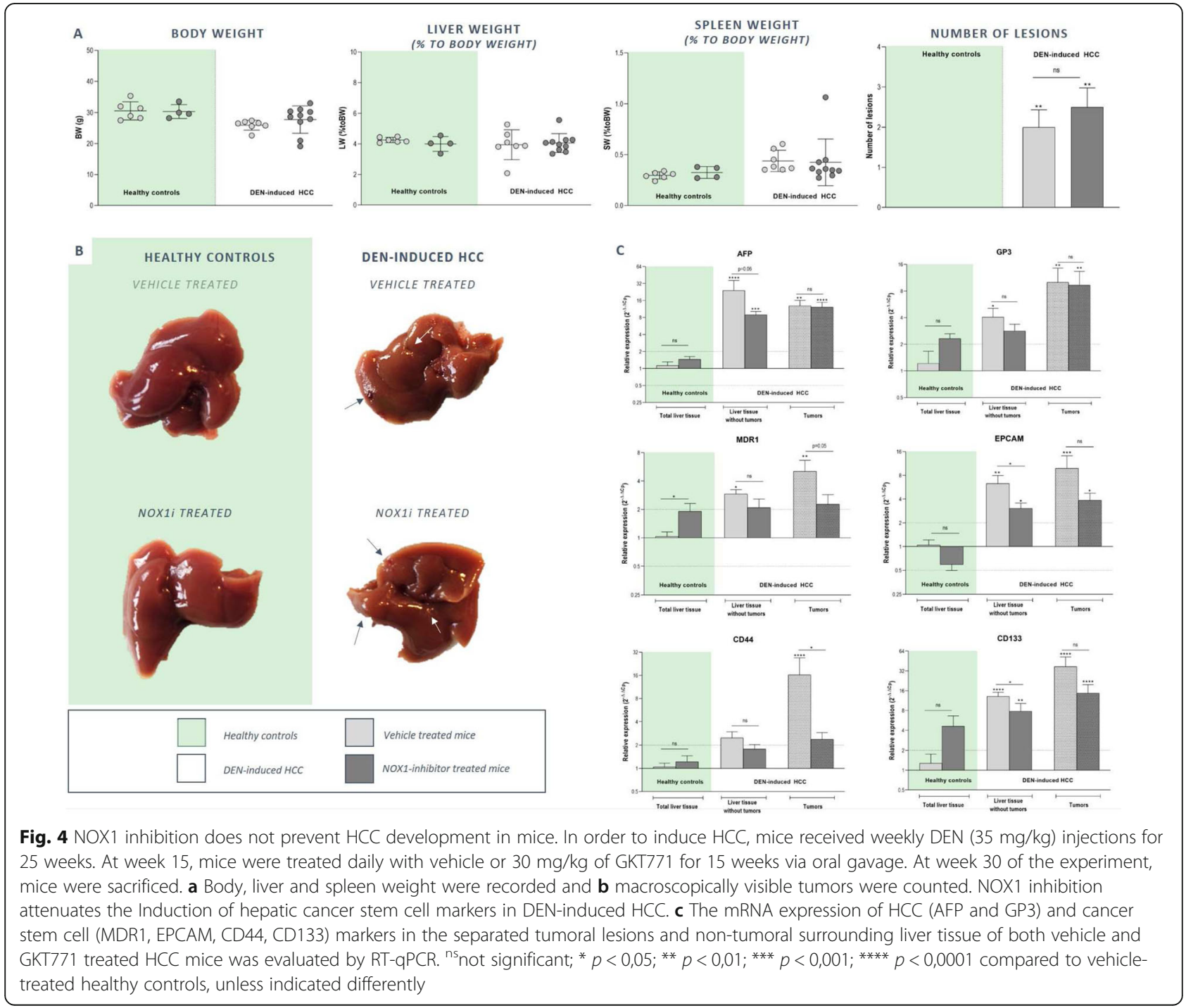




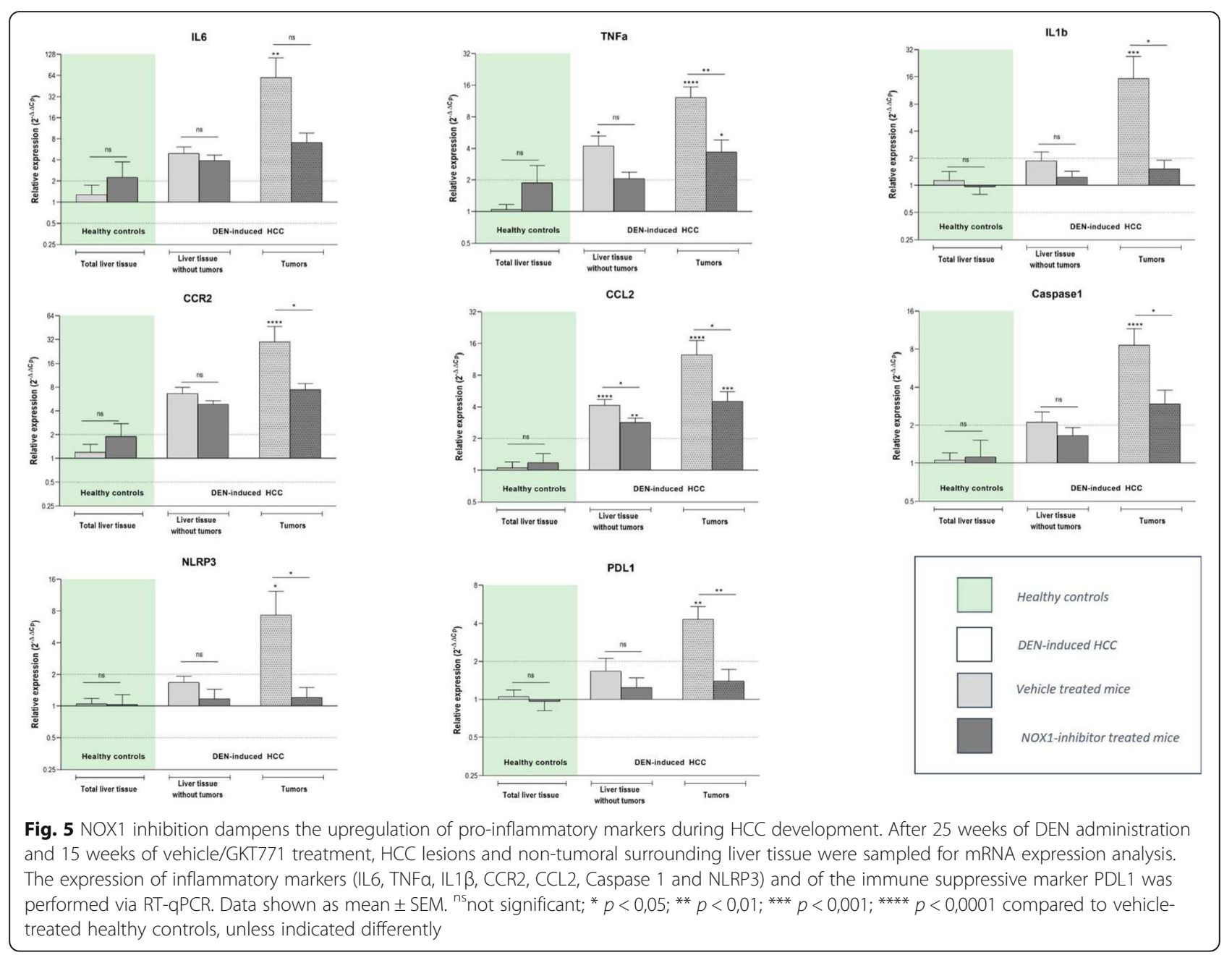

performed. NOX1 inhibition was able to attenuate DENinduced induction of both angiogenic (CD31, END, iCAM, vCAM) and fibrotic ( $\alpha$ SMA, COL1A, TGF $\beta$ ) markers (Fig. 6a-b). Histological analysis of liver fibrosis confirmed this anti-fibrotic effect of NOX1 inhibition early in DEN-induced HCC development (Fig. 6c).

\section{Early treatment and twice daily dosing of the NOX1 inhibitor is able to attenuate the progression of advanced HCC}

To evaluate the therapeutic potential of NOX1 inhibition in advanced HCC, two treatment regimens were set-up including an early and delayed treatment protocol (Fig. 1b). In both treatment regimens, DEN administration induced macroscopically visible tumoral lesions in the liver, while in the saline-treated control group no lesions were detected (Fig. 7a-b). Early treatment and twice daily dosing of GKT771 during advanced HCC resulted in reduced HCC lesions compared to no treatment (Fig. 7a-b). This was confirmed by less induced expression of the HCC markers AFP and GP3, both in the early (twice daily dosing) and delayed (single daily dosing) treatment group compared to untreated HCC mice (Fig. 7c). Assessment of the TME of advanced HCC liver tissue showed induction of markers involved in inflammation (IL1 $\beta$, TNF $\alpha$, IL6, CCL2, CCR2), inflammasome activation (Caspase 1, NLRP3, iNOS), immune suppression (PDL1), angiogenesis (END, CD31, iCAM, vCAM) and fibrosis ( $\alpha$ SMA, TGF $\beta$, COL1A) compared to healthy control livers (Figs. 11, 12 and 13A, light grey bars). In early twice daily dosed treated HCC mice, a (partial) loss of significant induction of IL1 $\beta$, TNF $\alpha$, CCL2, CCR2, Caspase 1 and NLRP3 in the HCC lesions could be observed (Fig. 8a). This was also confirmed by multiplex analysis showing reduced CCL2, TNF and IL6 production in NOX1i treated mice. Furthermore, treatment with NOX1 inhibition resulted in downstream inhibited ROS production in both treatment regimen (Fig. 8b). Expression of angiogenic marker vCAM was less induced in both the non-cancerous 


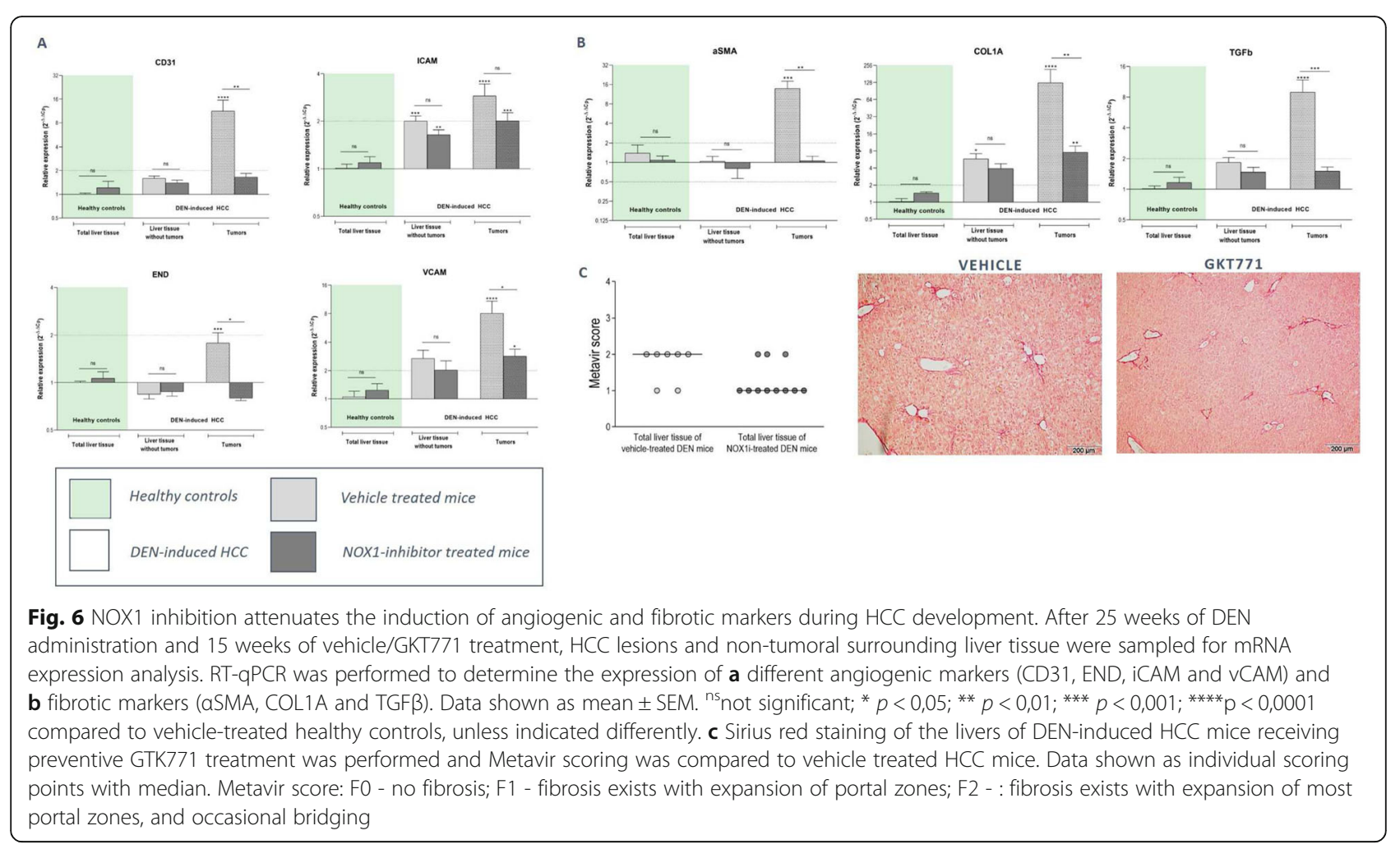

surrounding liver tissue and the HCC lesions of early twice daily treated HCC mice (Fig. 9a). Fibrosis was attenuated in both early and delayed GKT771 treated HCC mice, indicated by a (partial) loss of significant induction of COL1A and TGF $\beta$ expression in the surrounding liver, HCC lesions and total liver tissue (Fig. 9b). Furthermore, both treatment regimens resulted in a reduced Metavir score compared to untreated HCC mice (Fig. 9c).

\section{Discussion}

HCC related morbidity and mortality continues to rise as approximately forty percent of HCC patients have advanced underlying liver disease and are not eligible for potentially curative treatment options. The poor prognosis of advanced HCC is partly due to the limited efficacy and many adverse events of existing systemic treatments [1]. Consequently, there is an absolute medical need for the development and evaluation of new targeted therapies, which could also potentiate the clinical benefits of current systemic therapies. Our current study evaluated the effect of chemical NOX1 inhibition on the development of HCC and its potential as therapeutic strategy with focus on interference with the TME.

The development and progression of HCC occurs in the context of a complex microenvironment associated with many types of cellular stress. These stress pathways and their molecular mediators could serve as adequate candidate targets for such adjuvant systemic treatment strategies. In particular, due to the massive oxygen consumption in the growing tumor, hypoxia is a prevalent feature of the hepatic TME. In a hypoxic environment, persistent ROS accumulation induces inflammatory responses, resulting in genetic instability, chromosomal damage, and tumor development and metastasis. These increased amounts of ROS are generated by nonmitochondrial sources such as NADPH oxidase (NOX) enzymes [29]. High NOX1 levels have been shown to correlate with poor prognosis of HCC patients [24, 25]. Interestingly, in an experimental colon carcinoma model, treatment with a NOX1 inhibitor (GKT771) in combination with an anti-PD1 immune checkpoint inhibitor had an additional inhibitory effect on tumor growth, which suggest a possible therapeutic capacity of combining NOX1 inhibitors in other solid tumors such as HCC [31]. However, studies on this potential benefit of NOX1 inhibition in the prevention or treatment of HCC are still limited.

We first assessed the potential direct cytotoxic effects of NOX1 inhibition on human HCC cells by subjecting Huh7 and Hep3B cells to various concentrations of GKT771. Our results suggest a reduced cellular activity of these human HCC cell lines without cytotoxicity. However, this was not the case in the murine Hepa1-6 cell line, were no concentration-dependent reduction of cellular activity could be detected and cytotoxicity was 


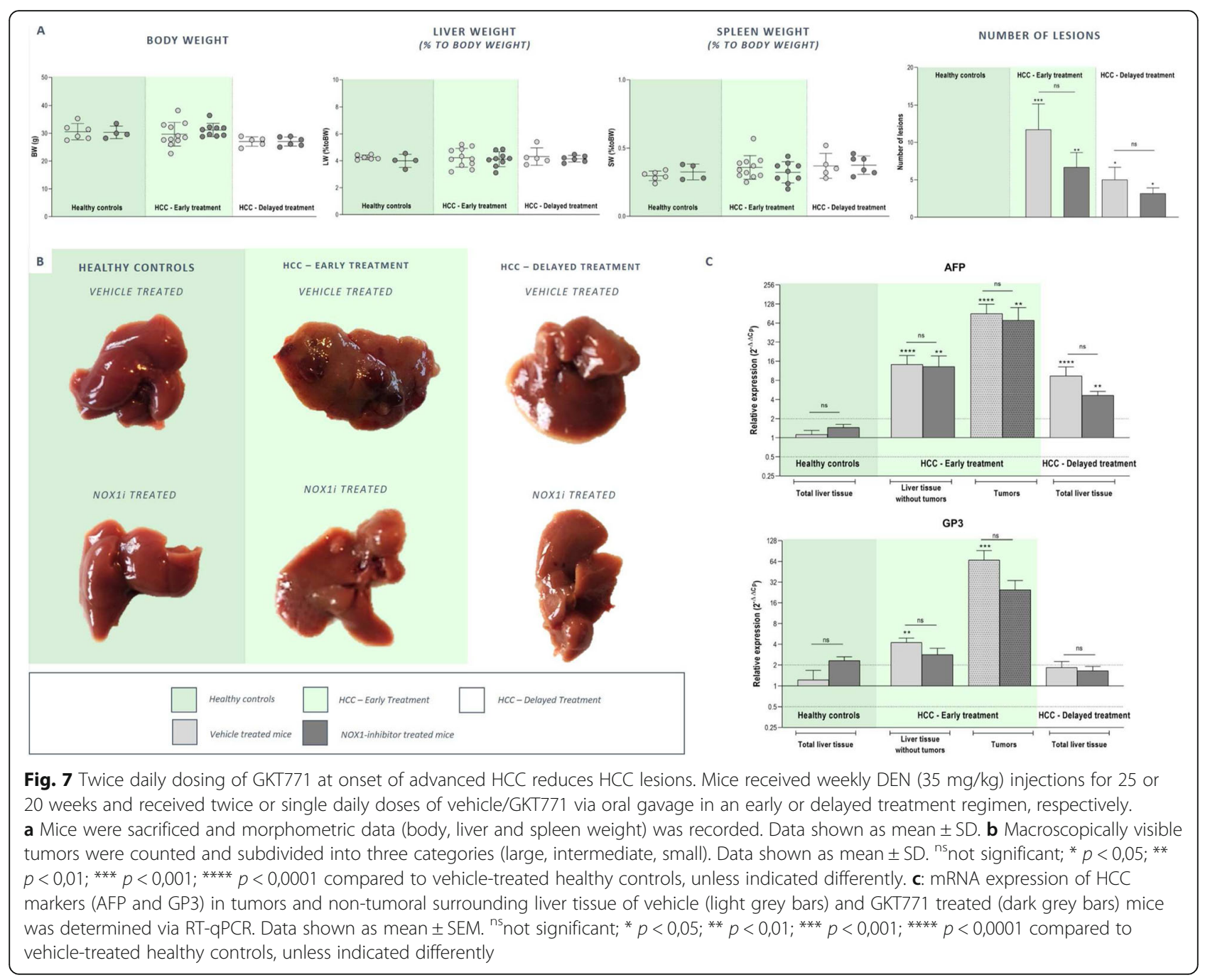

induced at the highest GKT771 concentration. These data suggest a different sensitivity of human and murine HCC cell lines in in vitro NOX1 inhibition.

We next wanted to investigate the anti-tumoral effect of NOX1 inhibition in an in vivo setting of orthotopic HCC in the context of a complex microenvironment. Therefore, we used a DEN-induced HCC mouse model to investigate whether chemical NOX1 inhibition is able to reduce HCC development. While we did not observe a reduction in HCC lesions in this preventive setting, NOX1i reduced the induction of tumoral stemness markers indicating the involvement of NOX1 in tumor aggressiveness. Liu et al. [29] previously stated that tumor hypoxia accelerates the aggressiveness of HCC cells due to the close relationship between ROS on the one hand, and EMT, tumor progression, invasiveness, angiogenesis, phenotype conversion and distant metastasis on the other hand. The insufficient oxygen amount in a hypoxic microenvironment limits tumor cell division, facilitates transition of malignant cells towards a more metastatic phenotype and endorses treatment resistance, in which cancer stem cells have been proven to play an important role. Additionally, high expression of NOX1 has been associated with HCC progression and aggressiveness [30].

In order to be able to translate results to a more clinical setting, two treatment regimens of NOX1i were evaluated in advanced/established HCC. Here, early treatment with a double daily dose of NOX1i resulted in an attenuation of HCC progression, which confirms the results published by Liang et al. showing that NOX1-/knockout mice or WT mice given DEN followed by the NOX-1 inhibitor ML171 developed fewer and smaller tumors after DEN injection. Additional to the investigation of cancerous traits of HCC, we focused on the effects of GKT771 on the tumoral microenvironment during HCC development. Interestingly, proinflammatory and angiogenic markers were less induced and fibrosis attenuated upon NOX1 inhibition during HCC progression in mice. Both our preventive and 


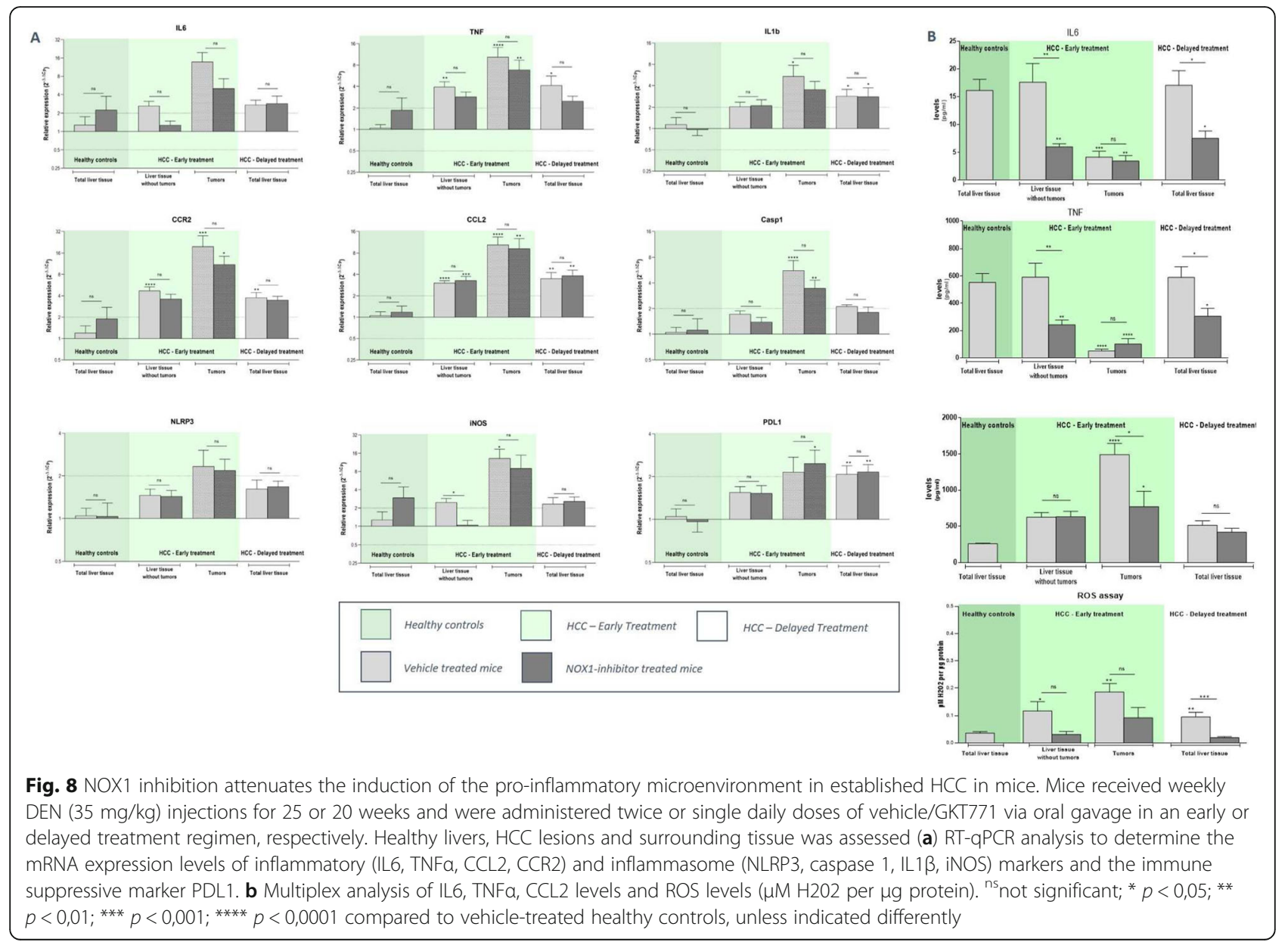

therapeutic studies confirm the ability of NOX1 inhibition to reduce the induction of a pro-inflammatory, angiogenic and pro-fibrotic microenvironment. For the DEN-induced HCC mouse model, it has been shown that NOX1 knockout mice exhibit equal amounts of hepatic DNA damage compared to wild type mice. This suggests that the carcinogenic effect of DEN is not only induced by DNA damage but in addition, ROS use a different mechanism of action generating hepatocyte injury, cell death, inflammation, and compensatory proliferation and fibrosis in the pathogenensis of DEN-induced HCC [26]. As both preventive and therapeutic GKT771 treatment in DEN-induced HCC attenuate the development of a pro-tumorigenic, and especially pro-fibrotic, microenvironment, NOX1 inhibition potentially possesses an adjuvant value to currently tested and available HCC therapies. The TME composes a biological barrier around solid cancers that prevents immunotherapy from effectively working. The TME is acidic, hypoxic and full of toxins and acts like a barricade that is able to fend off or chemically assault cancer-killing immune cells [31]. Furthermore, it has been shown that the TME mediates the resistance of $\mathrm{HCC}$ towards tyrosine kinase inhibitors such as Sorafenib, via the regulation of cell stemness, mesenchymal state of tumor cells and epigenetic mechanisms [32].

Different hepatic cell types, including hepatocytes, HSCs and KCs, express NOX1 [8, 22, 33]. However, Liang et al. recently published that NOX1 expression in macrophages, but not in other hepatic cell types, mediates their tumorpromoting activity [26]. We observed that primary murine BMDMs treated with GKT771 displayed a significant enhanced mitochondrial metabolic state, associated with plasma membrane disruption, both in the presence and absence of LPS, suggesting a moderate direct toxic effect of NOX1 inhibition in these immune cells. Therefore, we further assessed the effect of NOX1 inhibition on the functional phenotype of LPS-stimulated BMDMs and the human THP1 monocyte cell line. Remarkably, the LPSinduced increase in expression of inflammatory markers was attenuated during NOX1 inhibition by GKT771 treatment. Our in vitro results indeed suggest that direct chemical NOX1 inhibition does not primarily targets hepatic tumor cells, as only a slight reduction in metabolic activity in human HCC cells and only cytotoxic effects at the highest concentration in murine HCC cells could be 


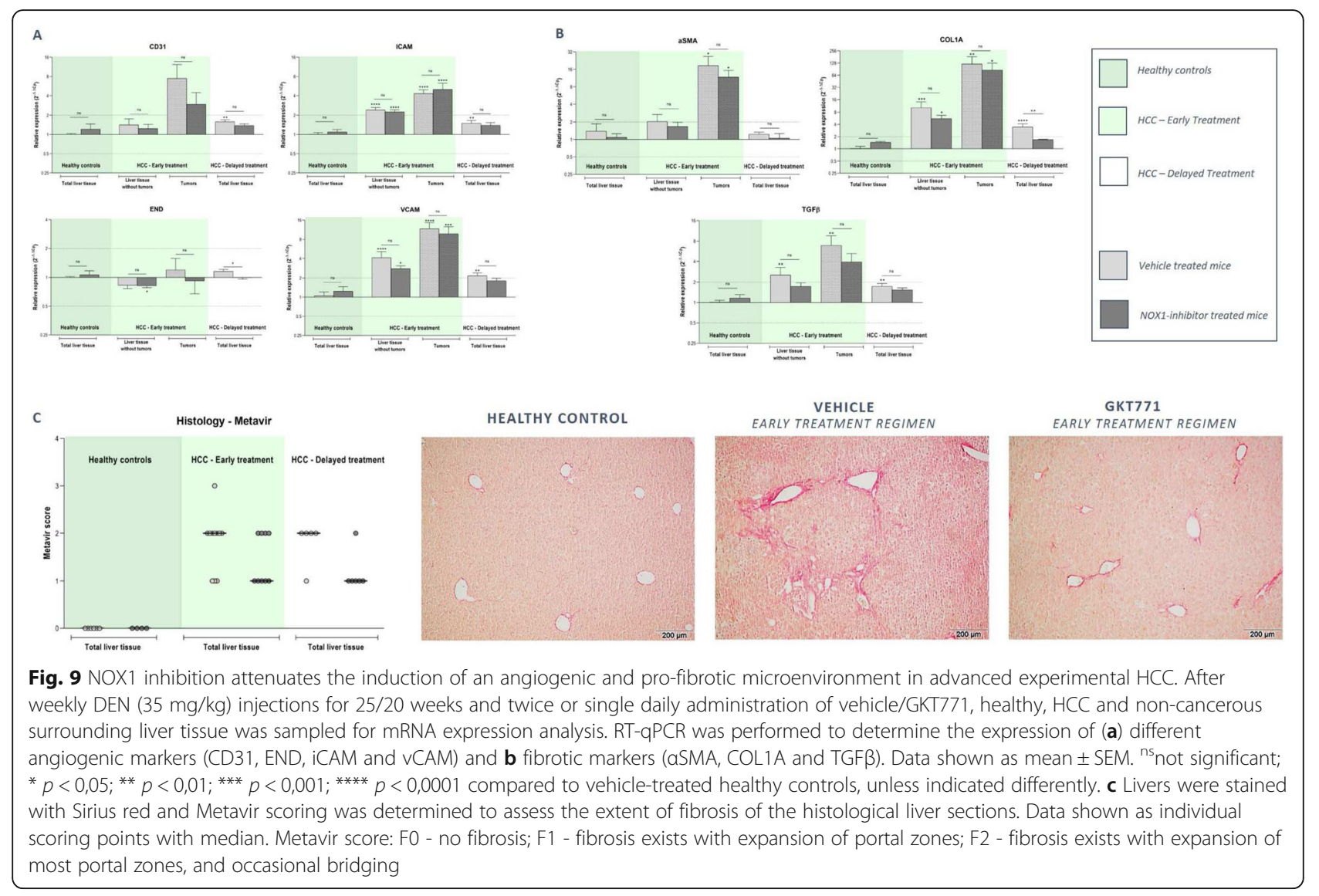

observed. This might indicate that our observed effects in vivo might also be mediated by influencing the polarization of cells characterizing the TME, as also published by Liang et al..

Our results of overall safety of NOX1 inhibition on human HCC cells, the effect of NOX1 inhibition on proinflammatory macrophage polarization and the attenuated development of a pro-tumorigenic environment by NOX1 inhibition in experimental HCC, suggests this might be a very promising adjuvant therapeutic strategy in the treatment of advanced HCC.

\section{Abbreviations}

BMDM: Bone-marrow derived macrophages; DEN: Diethylnitrosamine; DMSO: Dimethylsulfoxide; EMT: Epithelial-mesenchymal transition; HCC: Hepatocellular carcinoma; HSCs: Hepatic stellate cells; IP: Intraperitoneal; KCs: Kupffer cells; LDH: Lactate dehydrogenase; LPS: lipopolysaccharide; MTT: 3-(4,5-dimethylthiazol-2-yl)-2,5-difenyltetrazolium bromide; NOX: NADP H oxidase; NOX1i: NOX1 inhibition; ROS: Reactive oxygen species; RTqPCR: Reverse transcriptase quantitative real-time polymerase chain reaction; TME: Tumor microenvironment; WT: Wild type

\section{Acknowledgements}

The authors thank Petra Van Wassenhove, Inge Van Colen, Els Van Deynse and Sophie Vermaut for their technical assistance. The NOX1 inhibitor GKT771 was kindly provided by Genkyotex, France.

\section{Authors' contributions}

AV: Conceptualization, Methodology, Validation, Formal analysis, Investigation, Writing - original draft, Writing - review \& editing, Visualization. HD: Conceptualization, Methodology, Validation, Formal analysis, Investigation, Writing - original draft, Writing - review \& editing, Visualization. BV: Methodology, Writing - review \& editing. HW: Conceptualization, Supervision, Writing - review \& editing, Funding acquisition. LD: Conceptualization, Methodology, Writing - original draft, Writing - review \& editing, Supervision, Funding acquisition . The author(s) read and approved the final manuscript..

\section{Funding}

This work was supported by a grant from Kom op tegen Kanker (Stand up to Cancer), the Flemish cancer society. AV is supported by a Doctoral Scholarship of Special Research Fund, Ghent university, Belgium. HD is a clinical researcher of the Research Foundation Flanders (FWO), Belgium. HW is a senior clinical researcher of the Research Foundation Flanders (FWO).

\section{Availability of data and materials}

The data during and/or analysed during the current study available from the corresponding author on reasonable request.

\section{Ethics approval}

All animal experiments were reviewed and approved by the Animal Ethics Committee of the Faculty for Medicine and Health Sciences, University Ghent (ECD18/50).

\section{Consent for publication}

Not applicable.

\section{Competing interests}

The authors declare that they have no competing interests. 
Received: 7 August 2020 Accepted: 11 January 2021

Published online: 23 January 2021

\section{References}

1. European Association for the Study of the Liver. Electronic address eee, European Association for the Study of the L. EASL Clinical Practice Guidelines: Management of hepatocellular carcinoma. Journal of hepatology. 2018;69(1):182-236.

2. de Mochel NS, Seronello S, Wang SH, Ito C, Zheng JX, Liang TJ, et al. Hepatocyte $\mathrm{NAD}(\mathrm{P}) \mathrm{H}$ oxidases as an endogenous source of reactive oxygen species during hepatitis C virus infection. Hepatology. 2010;52(1):47-59.

3. Matsumoto M, Zhang J, Zhang X, Liu J, Jiang JX, Yamaguchi K, et al. The NOX1 isoform of NADPH oxidase is involved in dysfunction of liver sinusoids in nonalcoholic fatty liver disease. Free Radic Biol Med. 2018;115: 412-20.

4. Kono H, Rusyn I, Yin M, Gabele E, Yamashina S, Dikalova A, et al. NADPH oxidase-derived free radicals are key oxidants in alcohol-induced liver disease. J Clin Investig. 2000;106(7):867-72.

5. De Minicis S, Seki E, Paik YH, Osterreicher $\mathrm{CH}$, Kodama Y, Kluwe J, et al. Role and cellular source of nicotinamide adenine dinucleotide phosphate oxidase in hepatic fibrosis. Hepatology. 2010;52(4):1420-30.

6. Paik $\mathrm{YH}$, Iwaisako $\mathrm{K}$, Seki $\mathrm{E}$, Inokuchi S, Schnabl B, Osterreicher $\mathrm{CH}$, et al. The nicotinamide adenine dinucleotide phosphate oxidase (NOX) homologues NOX1 and NOX2/gp91(phox) mediate hepatic fibrosis in mice. Hepatology. 2011;53(5):1730-41.

7. Chocry M, Leloup L. The NADPH oxidase family and its inhibitors. Antioxidants \& redox signaling. 2019.

8. Bedard K, Krause KH. The NOX family of ROS-generating NADPH oxidases: physiology and pathophysiology. Physiol Rev. 2007;87(1):245-313.

9. Nauseef WM. Biological roles for the NOX family NADPH oxidases. J Biol Chem. 2008;283(25):16961-5.

10. De Minicis S, Brenner DA. NOX in liver fibrosis. Arch Biochem Biophys. 2007; 462(2):266-72

11. Sasaki Y. Does oxidative stress participate in the development of hepatocellular carcinoma? J Gastroenterol. 2006;41(12):1135-48.

12. Jo M, Nishikawa T, Nakajima T, Okada Y, Yamaguchi K, Mitsuyoshi H, et al. Oxidative stress is closely associated with tumor angiogenesis of hepatocellular carcinoma. J Gastroenterol. 2011;46(6):809-21.

13. Bertram K, Valcu CM, Weitnauer M, Linne U, Gorlach A. NOX1 supports the metabolic remodeling of HepG2 cells. PLoS One. 2015;10(3):e0122002.

14. Dou C, Xu Q, Liu J, Wang Y, Zhou Z, Yao W, et al. SHMT1 inhibits the metastasis of HCC by repressing NOX1-mediated ROS production. Journal of experimental clinical cancer research: CR. 2019;38(1):70.

15. Teufelhofer O, Parzefall W, Kainzbauer E, Ferk F, Freiler C, Knasmuller S, et al. Superoxide generation from Kupffer cells contributes to hepatocarcinogenesis: studies on NADPH oxidase knockout mice. Carcinogenesis. 2005;26(2):319-29.

16. Fiaschi T, Chiarugi P. Oxidative stress, tumor microenvironment, and metabolic reprogramming: a diabolic liaison. Int J Cell Biol. 2012;2012: 762825.

17. Landry WD, Cotter TG. ROS signalling, NADPH oxidases and cancer. Biochemical Society transactions. 2014;42(4):934-8.

18. Roy K, Wu Y, Meitzler JL, Juhasz A, Liu H, Jiang G, et al. NADPH oxidases and cancer. Clin Sci (Lond). 2015;128(12):863-75.

19. Aoyama T, Paik YH, Watanabe S, Laleu B, Gaggini F, Fioraso-Cartier L, et al. Nicotinamide adenine dinucleotide phosphate oxidase in experimental liver fibrosis: GKT137831 as a novel potential therapeutic agent. Hepatology. 2012;56(6):2316-27.

20. Jiang JX, Chen X, Serizawa N, Szyndralewiez C, Page P, Schroder K, et al. Liver fibrosis and hepatocyte apoptosis are attenuated by GKT137831, a novel NOX4/NOX1 inhibitor in vivo. Free Radic Biol Med. 2012;53(2):289-96.

21. Lan T, Kisseleva T, Brenner DA. Deficiency of NOX1 or NOX4 Prevents Liver Inflammation and Fibrosis in Mice through Inhibition of Hepatic Stellate Cell Activation. PLoS One. 2015;10(7):e0129743.

22. Paik YH, Kim J, Aoyama T, De Minicis S, Bataller R, Brenner DA. Role of NADP H oxidases in liver fibrosis. Antioxid Redox Signal. 2014;20(17):2854-72.

23. Lambeth JD, Kawahara T, Diebold B. Regulation of Nox and Duox enzymatic activity and expression. Free Radic Biol Med. 2007;43(3):319-31.

24. Eun HS, Cho SY, Joo JS, Kang SH, Moon HS, Lee ES, et al. Gene expression of NOX family members and their clinical significance in hepatocellular carcinoma. Sci Rep. 2017;7(1):11060.
25. Ha SY, Paik YH, Yang JW, Lee MJ, Bae H, Park CK. NADPH Oxidase 1 and NADPH Oxidase 4 Have Opposite Prognostic Effects for Patients with Hepatocellular Carcinoma after Hepatectomy. Gut Liver. 2016;10(5):826-35.

26. Liang S, Ma HY, Zhong Z, Dhar D, Liu X, Xu J, et al. NADPH Oxidase 1 in Liver Macrophages Promotes Inflammation and Tumor Development in Mice. Gastroenterology. 2018.

27. Pollutri D, Patrizi C, Marinelli S, Giovannini C, Trombetta E, Giannone FA, et al. The epigenetically regulated miR-494 associates with stem-cell phenotype and induces sorafenib resistance in hepatocellular carcinoma. Cell death disease. 2018;9(1):4.

28. Heindryckx F, Mertens K, Charette N, Vandeghinste B, Casteleyn C, Van

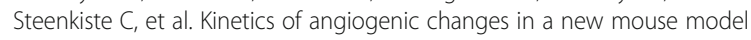
for hepatocellular carcinoma. Mol Cancer. 2010;9:219.

29. Liu Z, Tu K, Wang Y, Yao B, Li Q, Wang L, et al. Hypoxia Accelerates Aggressiveness of Hepatocellular Carcinoma Cells Involving Oxidative Stress, Epithelial-Mesenchymal Transition and Non-Canonical Hedgehog Signaling. Cellular physiology and biochemistry: international journal of experimental cellular physiology, biochemistry, and pharmacology. 2017;44(5):1856-68.

30. Abd Allah MEG. Immuohistochemical expression and significance of NADPH oxidase 1 and CXCR4 in hepatitis C virus-induced hepatocellular carcinoma. Egyptian Journal of Pathology. 2018;38(1):120-5.

31. Tang H, Qiao J, Fu YX. Immunotherapy and tumor microenvironment. Cancer Lett. 2016;370(1):85-90.

32. Chen J, Duda DG. Overcoming sorafenib treatment-resistance in hepatocellular carcinoma: A future perspective at a time of rapidly changing treatment paradigms. EBioMedicine. 2020;52:102644.

33. Reinehr R, Becker S, Eberle A, Grether-Beck S, Haussinger D. Involvement of $\mathrm{NADPH}$ oxidase isoforms and Src family kinases in CD95-dependent hepatocyte apoptosis. J Biol Chem. 2005;280(29):27179-94.

\section{Publisher's Note}

Springer Nature remains neutral with regard to jurisdictional claims in published maps and institutional affiliations.

\section{Ready to submit your research? Choose BMC and benefit from:}

- fast, convenient online submission

- thorough peer review by experienced researchers in your field

- rapid publication on acceptance

- support for research data, including large and complex data types

- gold Open Access which fosters wider collaboration and increased citations

- maximum visibility for your research: over $100 \mathrm{M}$ website views per year

At BMC, research is always in progress.

Learn more biomedcentral.com/submissions 